\title{
Hydroids on a Caribbean sea horse
}
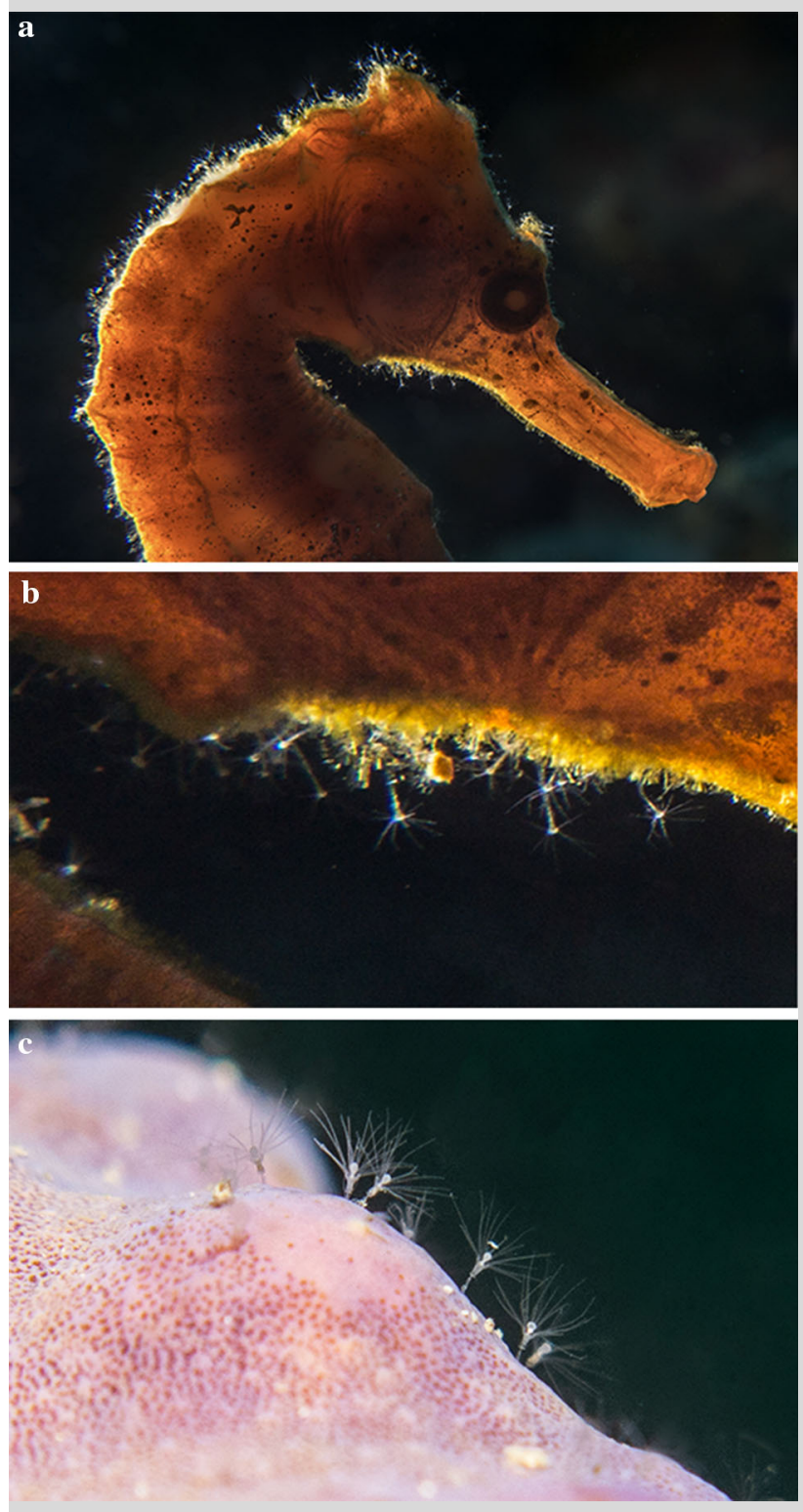

Fig. 1 a Hippocampus reidi colonized by hydroids. b Higher magnification of the Hydrozoa individuals on Hippocampus reidi extending their tentacles. c Hydroids colonizing Aplysina archeri sponge
Hydroid species (Cnidaria, Hydrozoa) are commonly found as epibionts on organisms within the phyla Porifera, Cnidaria, Bryozoa, Annelida, and Mollusca. A few have also been reported as epibionts of fish, with two reports of associations between hydroids and the family Syngnathidae, which includes pipefishes, sea horses, and seadragons. The hydrozoan Gonothyraea loveni was found on a straightnose pipefish, Nerophis ophidion, in the Gulf of Gdańsk (Baltic Sea; Dziubińska and Sapota 2013), and negatively impacted its ability to swim, while the hydrozoan Hydrichthys mirus produced thin plates on the skin of a Choeroichthys brachysom pipefish from the Bismarck Sea (Papua New Guinea) to parasitize the host (Boero et al. 1991). In both cases, the Syngnathidae hosts died shortly after the observations.

In June 2018, hydrozoan zooids were found for the first time colonizing a sea horse (Hippocampus reidi) at a depth of $26 \mathrm{~m}$ in the Caribbean Sea (Roatan, Honduras; Fig. 1a, b). Unlike what was observed previously, small hydroids (1-2 mm) were distributed across the surface of the sea horse, which did not appear to be in poor body condition nor have balance issues. However, because the observation was made on the reef, while the fish was attached to an Amphimedon compressa sponge, we have no information on the ultimate fate of the sea horse. Visual analyses of the sea horse-associated hydroids suggest they belong to the family Campanulariidae (Leptothecata, Hydrozoa) and most likely to the genus Clytia. Members of Clytia are poorly described, and further morpho-molecular studies are needed for accurate species-level identification.

Hippocampus reidi, one of three species of sea horses inhabiting the Caribbean Sea, utilizes various structures as holdfasts, including sponges, which are known to be suitable substrate for hydroids (Fig. 1c), and may have served as a mechanism for the acquisition and possible subsequent dispersion of hydroids. This sea horse species is classified by the IUCN as 'near-threatened,' and its presence in Roatan waters has declined approximately $30 \%$ over the past 10 years, enhancing the importance of this discovery, particularly if the hydroids do not harm their host.

\section{References}

Boero F, Bouillon J, Gravili C (1991) The life cycle of Hydrichthys mirus (Cnidaria: Hydrozoa: Anthomedusae: Pandeidae). Zool J Linn Soc 101:189-199

Dziubińska A, Sapota M (2013) Hydroid Gonothyraea loveni found on the straightnose pipefish (Nerophis ophidion) in the Gulf of Gdańsk-symbiosis, parasitism or biofouling? Oceanol Hydrobiol Stud 42:332-335

M. Monti (iD $(\bowtie)$. A. Giorgi · J. B. Olson

Department of Biological Sciences, The University of Alabama, Tuscaloosa, AL, USA

e-mail: mmonti@crimson.ua.edu 